\title{
Substance Use and Prevention Programs in Berlin's Party Scene: Results of the SuPrA-Study
}

\author{
Felix Betzler ${ }^{a} \quad$ Felicitas Ernst $^{\mathrm{a}} \quad$ Jonas Helbig ${ }^{\mathrm{a}} \quad$ Leonard Viohl $^{\mathrm{a}} \quad$ Lukas Roediger $^{\mathrm{a}}$ \\ Sarah Meister ${ }^{b}$ Nina Romanczuk-Seiferth ${ }^{a} \quad$ Andreas Heinz $^{a} \quad$ Andreas Ströhle $^{a}$ \\ Stephan Köhler ${ }^{a}$ \\ ${ }^{a}$ Charité Universitätsmedizin Berlin, Corporate Member of Freie Universität Berlin, Humboldt-Universität zu Berlin, \\ and Berlin Institute of Health, Institute of Psychiatry and Psychotherapy, Campus Charité Mitte, Berlin, Germany; \\ ${ }^{\mathrm{b}}$ Medical School Berlin, University for Health and Medicine, Berlin, Germany
}

\section{Keywords}

Substance use · Prevention · Party drugs · Nightlife · Berlin ·

Drugs $\cdot$ Drug checking $\cdot$ Clubs $\cdot$ Party scene

\begin{abstract}
Background: Berlin is internationally known for its nightlife. In a nation-wide and Europe-wide comparison, the use of legal and illegal substances is comparatively higher in Berlin than in other similar cities. However, few data exist about the drug use in the party scene. Objective: This study aims to assess the sociodemographic characteristics of Berlin's party scene and its patterns of substance use as well as expectations towards prevention in order to derive appropriate preventive measures. Methods: Using questionnaires, both online $(n=674)$ and in the field $(n=203)$, a total of 877 people of the Berlin party scene were interviewed. The questionnaires ascertained the demographic information of the participants and patterns of substance use in the scene. It also collected the demand for consulting services and personal assessments on the usefulness of prospective and existing prevention programs and offers. Results: The study participants were 29 years old (SD 7.5); $43 \%$ were female. Alcohol is the most common substance in the party scene, followed
\end{abstract}

(c) 2019 S. Karger AG, Basel

\section{E-Mail karger@karger.com www.karger.com/ear \\ KARGER}

by cannabis, MDMA/Ecstasy, amphetamine, cocaine, and ketamine. In this particular cohort, methamphetamine and "legal highs" did not play a major role. The most demanded preventive measure was more education about drugs and the so called drug-checking. Conclusions: Prevention in this area is both needed and requested, and an expansion of the existing programs (e.g., by so far politically controversial drug-checking) should be considered.

(c) 2019 S. Karger AG, Base

\section{Introduction}

The consumption of illicit substances as part of the nightlife has been reported in recent years, with studies in particular examining the techno-scene [1-3]. Chinet et al. [1] investigated substance use in the techno-scene of French-speaking Switzerland. The highest 30-days prevalence was found for alcohol (86.8\%), cannabis (53.8\%), ecstasy (3,4-Methylendioxy-N-methylamphetamin [MDMA]; 22.7\%), and cocaine (20.7\%).

In Germany, few existing studies have examined substance use in night-life $[2,4]$. One study examined the illegal substance use in the Munich electro-scene and 
discovered that with a lifetime prevalence of $80.7 \%$, cannabis was the most consumed substance, followed by MDMA (63.5\%), amphetamine (59.5\%), and cocaine (40.3\%) [2].

Throughout Germany, Berlin has the highest numbers of substance use: a representative inquiry stated that in 2012, the lifetime prevalence of illicit drug use was at $42.5 \%$ (30-days prevalence: approximately $6 \%, 12$-month prevalence: $12.2 \%$ ) [5]. The highest proportion of use was cannabis (12-month prevalence: $4.5 \%$ ), which was mostly consumed by young (under age 25 years), single adults with a lower educational background. Other illicit substances - such as MDMA (12-month prevalence: $0.4 \%$ ) or cocaine $(0.8 \%)$ - were mostly consumed by individuals aged 25-39 years. Illicit substances are also consumed more by men than by women [5].

One study that examined the techno-scene in European capitals reported that party-goers in Berlin used significantly more amphetamine, and significantly less cocaine [3]. The study also showed that the drug-specific prevalence is much higher in the nightlife sample than in the general population.

Berlin is commonly known for its music/dance clubs (many of which are open continuously on weekends), festivals, and after work parties in secret or private locations [6-8]. In a nation-wide comparison, the use of legal and illegal substances is comparatively higher in Berlin [5]. Despite this, existing data on current drug use (and the use of substances currently gaining relevance like gamma-hydroxybutyrate/gamma-butyro-1,4-lacton (GHB/GBL), ketamine and new psychoactive substances) are insufficient $[9,10]$.

In recent years, the loophole of the legal situation of new psychoactive substances being legal in Germany as long as they are chemically slightly different from already regulated substances, was partially closed in 2017 by introducing the NPS law, which regulates not only particular substances but also whole groups of substances [11]. However, it only regulates the 2 most popular NPS groups so far (synthetic cannabinoids and synthetic cathinones), leaving the door open for other groups of NPS to emerge. Thus, the legal situation for NPS in Germany is still heterogeneous and subject of discussion.

Due to the lack of data, there are no existing, coordinated preventions based on quantitative data in Berlin. An assessment of the current situation concerning substance use and sociodemographic characteristics of the consumers and their expectations towards the prevention and frontline services is thus important to be able to meet the needs of the target group.
The few existing prevention programs in the Berlin nightlife scene are partly offered by the specialist unit of drug prevention, with others being offered voluntarily [12]. All programs are experience-based rather than based on empirical data specifically assessing Berlin's nightlife.

The aim of the current work is to capture the sociodemographic characteristics of participants of the Berlin party scene and to examine their substance use and abuse. The substances consumed and the motivation to do so were also assessed. Furthermore, we explored the requests for additional prevention offers and what additional needs should be considered. Finally, the attitude towards existing prevention concepts and programs were evaluated.

\section{Methods}

In an effort to capture a high rate of responses, an online questionnaire was created and used [13], online supplementary Appendix, see www.karger.com/doi/10.1159/000501310. Simultaneously, to capture externally valid and immediate results, a physical paper and pencil version of the questionnaire was also used for respondents in the field. Data collection was carried out from September 9, 2017 until November 1, 2017, after approval by the ethical reviewer committee of Charité Universitätsmedizin Berlin (Application number: EA4/157/17).

The questionnaire contained questions related to demographic information, such as age, gender, sexual orientation, educational degree, and recent professional activities. Thirty-day and lifetime prevalence for legal and illegal substances were also compiled. To assess the consumption of specific substances, variables such as age of first consumption, thoughts and wishes on reducing consumption and motivation for consumption were ascertained as free text. Moreover, the questionnaire included statements on the relative risk perception of the 7 most common substances: cannabis, alcohol, amphetamine, MDMA, ketamine, cocaine, and GHB/GBL, which are based on the questionnaire of the European counselling center for Drugs and Drug Addiction [14]. The CAGE-screening questionnaire for alcohol and illicit drugs (CAGE-AID) was used to acquire potential problematic consumption [15]. The participants were also asked to indicate diagnosed psychiatric disorders.

On a 5-point Likert scale, the questionnaire inquired about the demand for consulting services and personal assessments of the usefulness of prospective and existing prevention programs. These questions were chosen on the basis of the guideline for addiction prevention in Berlin (2006) and existing national and international prevention approaches [12].

The online questionnaire was accessible via the platform SoSci Survey. The participants were directed towards the questionnaire via the newsletter of the included clubs, social media platforms, scene intern communication platforms, and online newspaper. In the field, data collection took place in dancing events, bars, clubs, and corresponding waiting lines.

The selection of the sampled clubs was determined by the size of the floor space $\left(>300 \mathrm{~m}^{2}\right.$; with help of the Clubkataster Berlin) and the popularity according to different online guides and rankings $[8,16]$. The rankings were pooled, and the biggest and most 
Fig. 1. Distribution of the recent professional activity and the highest academic achievement of the participants. Upper secondary school: university entrance degree, "Abitur". Intermediate secondary school: school leaving certificate, "Mittlerer Schulabschluss", lower secondary school: "Hauptschulabschluss".

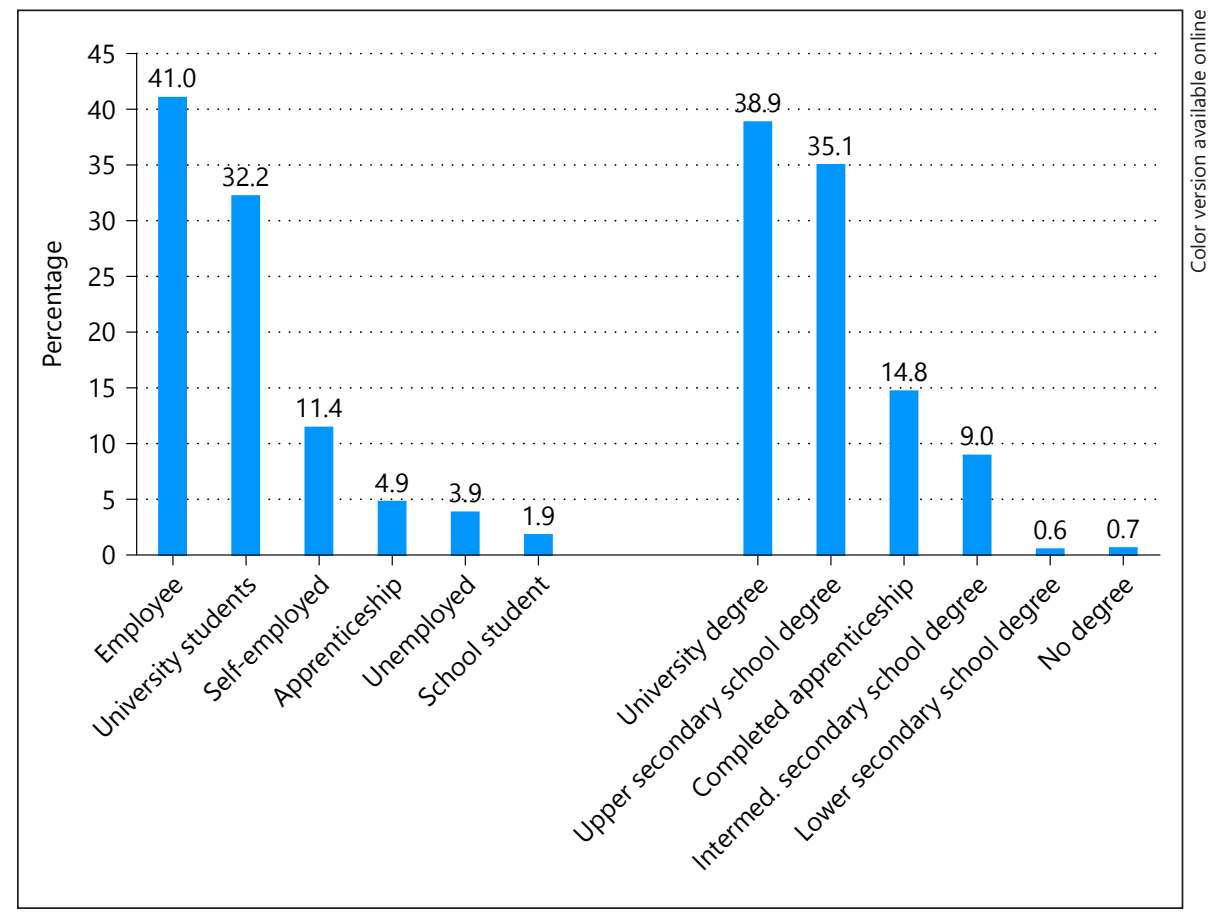

popular clubs were asked for participation in this study. The list of clubs was not narrowed down to specific types of music (e.g., techno) or sub-scenes (e.g., men who have sex with men-Scene).

The questionnaire was composed in German and English, and tested for its acceptance and understandability prior to being used. All participant gave informed consent prior to study participation.

The data were analyzed using SPSS version 25. A plausibility filter was created to exclude potentially false questionnaires. The filter screened the age of the respondents (15-70 years) and the age of first consumption (15-70), as the typical party scene subject to this survey is assumed to be within these parameters [3]. The minimum time for replying was set to $180 \mathrm{~s}$, as it seemed implausible to comprehensively fill out the questionnaire faster than that. The same criteria were used to filter the paper-pencil version, except the time to reply. Moreover, the questionnaire included 2 "control substances", that is, made-up names of substances that do not exist, to exclude participants who rush through the questionnaire ("lurker"). Participants who confirmed consumption of 2 non-existing "control substances" were excluded. The filter of the online questionnaire excluded 57 participants; the paper-pencil filter excluded 26 participants.

We carried out explorative data analyses with the demographic data, the prevalence of individual consumed substances, the CAGE-AID, and the questions on psychiatric disorders presented as descriptive data. To compare the 2 datasets, Mann-Whitney $U$ tests were performed. To assess group differences, we calculated Chi-square tests. The level of significance was set at $\alpha=0.05$. Spearman's correlations were conducted to correlate non-metric variables (different "motivations" to "psychiatric diagnoses" and to "need for counseling/prevention"). Here, a Bonferroni correction lowered the level of significance to.007. For the analysis of motivation for consumption $(n=2,742)$, the statements were categorized, and subsumed in clusters modified according to Boys et al. [17].

Substance Use and Prevention Programs in Berlin's Party Scene

\section{Results}

To evaluate the data quality regarding biases, the $2 \mathrm{da}-$ tasets of the 2 assessment methods (paper-pencil $n=203$, online version $n=674$ ) were compared. The results showed a good overlap of the 2 datasets, with no significant differences in gender distribution, and with similar patterns regarding the 30-day prevalence, 12-month and lifetime prevalence. Significant differences were observed on educational achievement and age (both times higher in the online-version, education: $U=61,490, p=0.046$, age: $U=51,282, p=0.002$, differences were moderate, Cramer's $\mathrm{V}<0.2)$. For further analysis, the results of both methods were pooled, resulting in 1 dataset of $n=877$ completed questionnaires. The following results refer to the pooled dataset.

\section{Sociodemographic Data}

The average respondent's age was 29 years (mean 28.9, SD 7.5), with $42.8 \%$ of the respondents being female. Most of the participants were residents of Berlin for at least 1 month $(84.4 \%, n=740)$, and $7.6 \%(n=67)$ of the respondents were classified as tourists. Figure 1 visualizes the recent professional activity and the highest educational level of the participants. Regarding sexual orientation, $76.3 \%$ $(n=669)$ stated that they were heterosexual, 9.7\% $(n=85)$ were homosexual, and $11.4 \%(n=100)$ were bisexual. 
Table 1. 30-Day, 12-month and lifetime prevalence of participants

\begin{tabular}{llll}
\hline Substance & 30 -Day, $\%$ & 12 -Month, $\%$ & Lifetime, \% \\
\hline Alcohol & 87.8 & 92.8 & 95.8 \\
Nicotine & 72.3 & 80.2 & 94.0 \\
Cannabis & 62.3 & 79.6 & 88.7 \\
Amphetamine & 50.3 & 73.8 & 84.3 \\
MDMA & 49.1 & 70.1 & 79.3 \\
Cocaine & 36.0 & 61.7 & 77.5 \\
Ketamine & 32.2 & 51.2 & 63.6 \\
LSD & 12.0 & 32.8 & 55.6 \\
GHB/GBL & 9.4 & 29.5 & 52.9 \\
Psilocybin & 6.7 & 17.3 & 32.1 \\
Benzodiazepines & 6.5 & 15.6 & 30.4 \\
Amyl nitrite & 4.3 & 12.1 & 29.2 \\
Opioid based pain reliver & 3.6 & 10.8 & 26.0 \\
Neuro-enhancer & 2.2 & 8.8 & 24.3 \\
Methamphetamine & 1.9 & 3.6 & 16.1 \\
Synthetic cathinones & 1.3 & 3.6 & 15.9 \\
Synthetic cannabinoids & 0.8 & 2.1 & 10.3 \\
Heroin & 0.5 & 0.7 & 4.6 \\
Others* & $/$ & $/$ & 22.2 \\
\hline
\end{tabular}

* Ten most popular substances stated in this category were, in descending order: 2C-B $(n=48)$, DMT $(n=$ $35)$, mephedrone $(n=12)$, nitrous oxide $(n=12)$, LSA $(n=11)$, kratom $(n=8)$, mescaline $(n=8)$, salvia divinorum $(n=8), \operatorname{MXE}(n=7)$, methoxetamine $(n=7)$. No 30-day/12-month prevalence assessed here.

MDMA: 3,4-methylendioxy-N-methylamphetamin; LSD: Lysergic acid diethylamide; GHB/GBL: gammahydroxybutyrate/gamma-butyro-1,4-lacton.

\section{Psychiatric Disorders}

Of all respondents, $20.4 \%$ stated to ever have had a psychiatric disorder. Among the specified diagnoses in the free-field response, affective disorders $(n=55)$ were the most prevalent, followed by anxiety disorders $(n=$ $19)$, addictive disorders $(n=16)$, eating disorders $(n=13)$, post-traumatic stress $\mathrm{d}(n=12)$, attention deficit hyperactivity disorder $(n=9)$, personality disorders $(n=9)$, and psychotic disorders $(n=4)$.

\section{Substance Use}

Alcohol showed the highest prevalence. Regarding illicit substances, cannabis was the most prevalent, followed by Amphetamine and MDMA. However, Synthetic Cannabinoids and Synthetic Cathinones (as a group of substances similar to Amphetamine and MDMA) were mentioned the least (except heroin). A Chi-square test showed that there was no difference in lifetime substance use between genders $\left(\chi^{2}[2, n=870]=\right.$ $1.16, p=0.56)$.

Table 1 shows the 30-day, 12-month, and lifetime prevalence of the participants per substance, respectively.

\section{Assessment of Prevention Offers and Programs}

Concerning the assessment of possibly useful as well as existing prevention concepts, all prevention programs which were listed in the questionnaire were found to be meaningful and were positively rated (Likert-scale from 0 "not meaningful at all" to 5 "very meaningful"). Among all concepts listed in the questionnaire, (a) "drug-checking" was rated as the most useful (4.7), followed by (b) safer use instructions (4.6) and (c) fixed consulting services, which can be visited in times of need (4.5). Further in descending order: (d) websites and forums with information about drug use (4.4), (e) training for social workers and teachers (4.3), (f) training for employees in the party scene for handling of drugs (4.2), (g) awareness through information in schools (4.2), (h) counselling and help at hand, for example, festivals, clubs, waiting lines (4.2), (i) specific drug counselling services for high-risk groups, for example, men who have sex with men (4.0).

\section{Age of First Consumption and Wish for Reduction}

The age of first consumption of cannabis was 17 years. For the other commonly consumed substances, the ages of first consumption were 21 years for amphetamines, 22 
Fig. 2. Mean of the age of first use in years. MDMA, 3,4-methylendioxy-N-methylamphetamin; GHB/GBL, gamma-hydroxybutyrate/gamma-butyro-1,4-lacton.

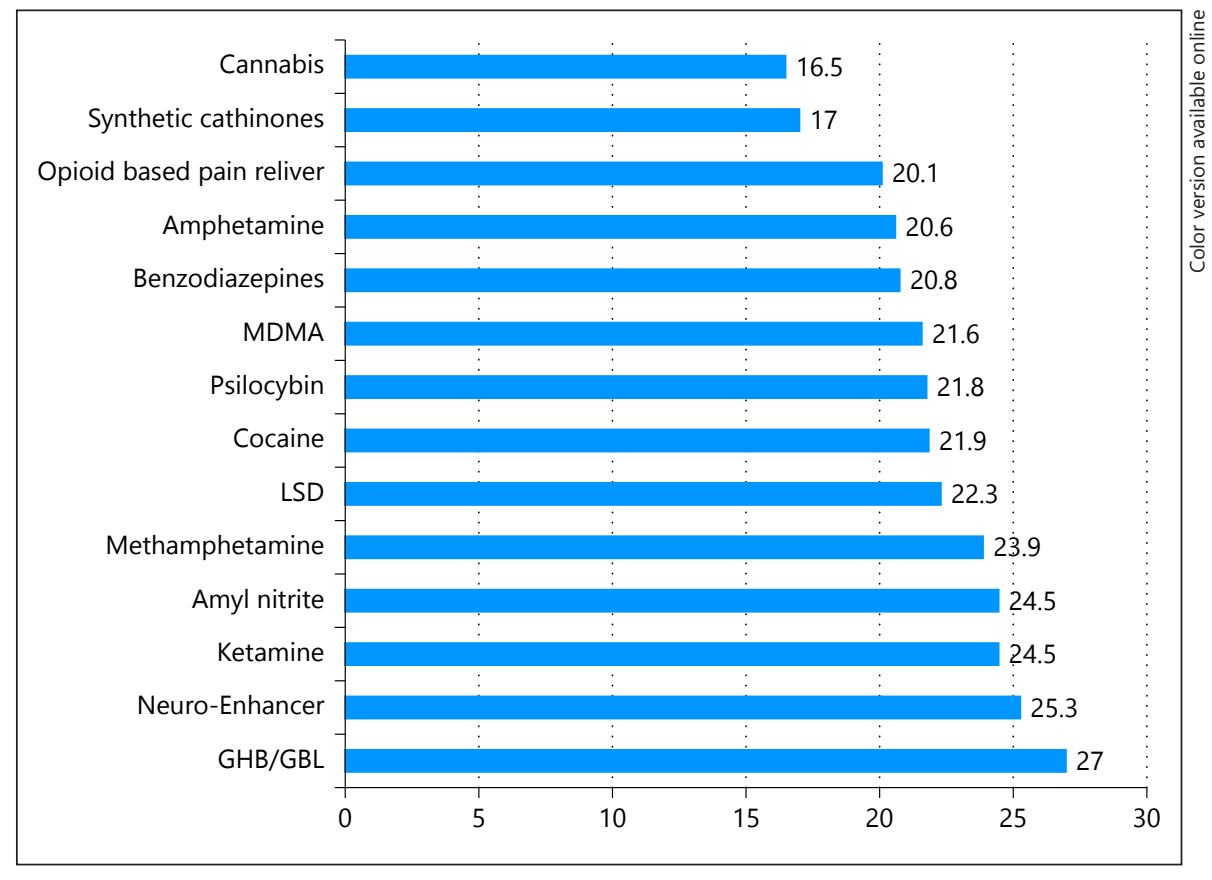

years for MDMA and cocaine, 25 years for ketamine, and 27 years for GHB/GBL (Fig. 2).

Among the most commonly consumed substances, where users also state motivation for change, GHB/GBL users showed the highest desire for reduction (53\%), followed by cocaine ( $49 \%)$, cannabis (41\%), and amphetamine users (38\%). Even though MDMA was widely represented, only $25 \%$ stated a desire for reducing consumption (Fig. 3).

A conspicuous consumption, according to the CAGE-AID, was displayed by $67.2 \%(n=589)$ of the participants. No gender difference was found, $\left(\chi^{2}[1, n=\right.$ $858]=4.06, p=0.13$ ).

Respondents who displayed a positive CAGE-AID more often stated to have had a psychiatric disorder (23.1\%) compared to those with a negative CAGE-AID $(16.5 \%), \chi^{2}(1, n=847)=4.83, p=0.03$. Furthermore, respondents with a positive CAGE-AID displayed a significant higher desire for addiction counselling than the respondents with a negative CAGE-AID (27.1 vs. $16 \%), \chi^{2}$ $(1, n=828)=12.3, p<0.001)$. Also, respondents with a conspicuous CAGE-AID more often stated the desire for reducing the consumption of their most commonly used drug, than respondents with a negative CAGE-AID (84.7 vs. $60.7 \%), \chi^{2}(1, n=793)=51.56, p<0.001$.

This difference was also found for the second most commonly used substance, $\chi^{2}(1, n=704)=44.64, p<$ 0.001 , and the third most commonly consumed substance, $\chi^{2}(1, n=614)=15.14, p<0.001$.

Substance Use and Prevention Programs in Berlin's Party Scene

\section{Motives of Consumption}

In 783 questionnaires (89.3\%), respondents provided details on motivations for the use of their most commonly used substances. The total number of 2,472 stated motivations were categorized into previously described clusters [17] presented in Figure 4.

Comprising the whole range of substances, most respondents stated that they use substances to change their mood (49.9\%), to gain physical effects (15.1\%) or to modulate or enhance perception (8\%). Social purposes were chosen by $3.8 \%$, self-medication by $3 \%$, modulating effects of other drugs by $0.3 \%$, and other motives by $5.1 \%$. A Spearman's correlation showed that there was no relation between the different motives and request for counseling/prevention. Suffering from a psychiatric diagnosis was positively correlated to the motive "self-medication" $(r=0.089, p=0.016)$ and negatively correlated to "mood change" $(r=-0.078, p=$ $0.035)$. However, following a conservative Bonferroni correction which lowers the level of significance to 0.007 , these results do not reach the (corrected) significance level.

\section{Discussion and Conclusion}

The results of this study showed a higher prevalence of substance use for most of the inquired substances in Berlin's nightlife than in other German and European countries. In descending order, the 30-day prevalence of the 


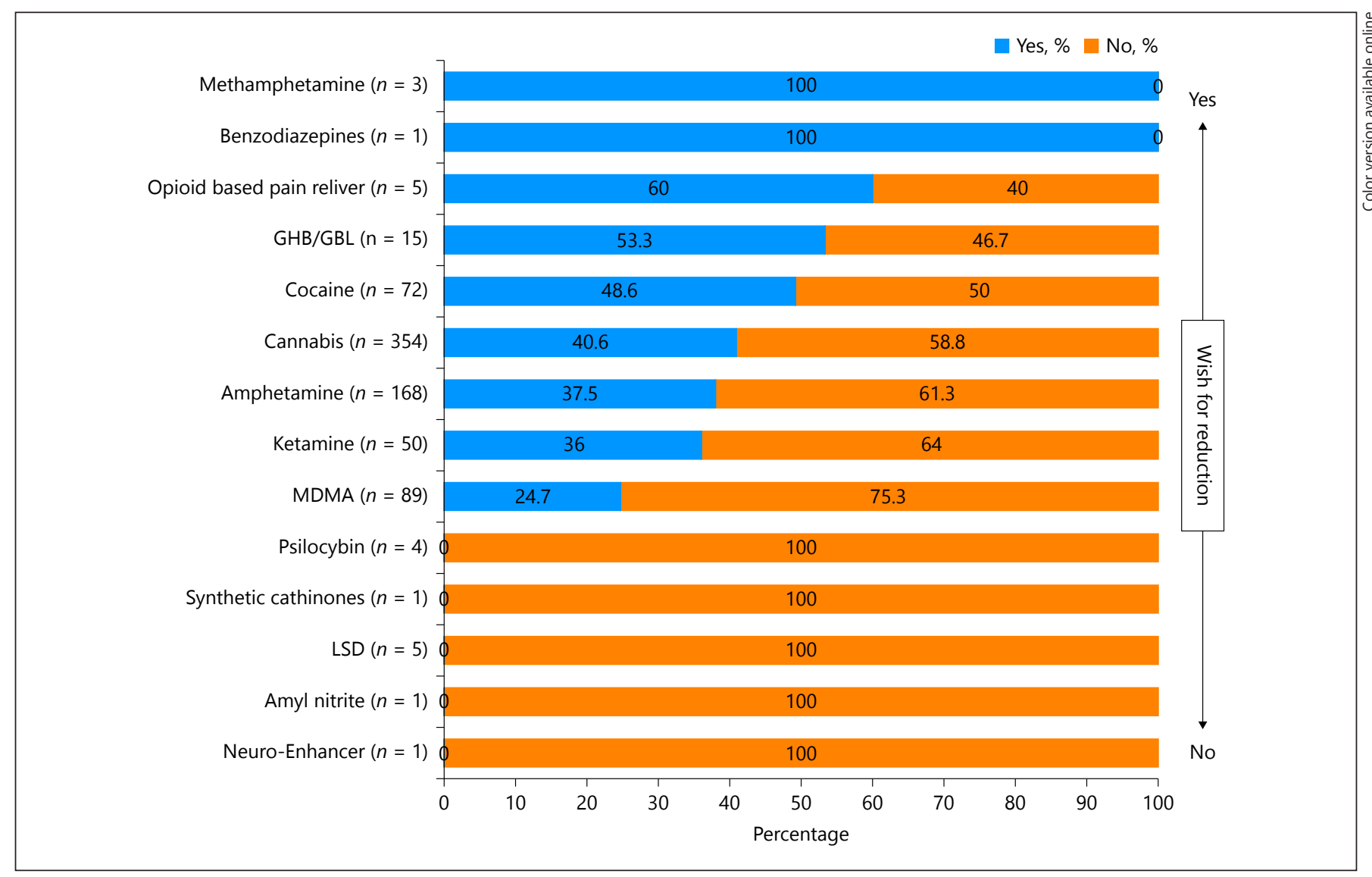

Fig. 3. Desire for reducing consumption, regarding the most frequently used substances. GHB/GBL, gammahydroxybutyrate/gamma-butyro-1,4-lacton; MDMA, 3,4-methylendioxy-N-methylamphetamin.

listed substances were: alcohol, cannabis, amphetamine, MDMA, cocaine, and ketamine, followed by LSD and GHB/GBL. Methamphetamine and new psychoactive substances were shown not to be popular in Berlin's party scene. These results in terms of rank of popularity show a high conformity with the Global Drug Survey [9] (e.g., 12-month-prevalence Methamphetamine SuPrA vs. GDS: cannabis 62.3 vs. $77.5 \%$, amphetamine 50.3 vs. $49.6 \%$, MDMA 49.1 vs. $50.1 / 57.1 \%$ (pills/powder), cocaine 36 vs. $45 \%$, ketamine 32.2 vs. $28.5 \%$, methamphetamine 1.9 vs. $1.0 \%)$.

A waste-water investigation in European central cities and capitals underpins the high consumption in Berlin presented in this study and complements the few epidemiological studies that allow to compare the results of our study to the German and European party scenes: it showed that residuals of party drugs in waste-water per inhabitant were the highest in Berlin compared to 4 other major German cities. The consumption of MDMA was documented the most. With respect to MDMA and amphetamine,
Berlin is also among the top ten cities in Europe. The highest amount of residuals of MDMA per inhabitant per day was registered in Amsterdam. For amphetamine, Eindhoven showed the highest numbers and for cocaine, Zurich ranked highest [18].

Reflecting the results from the waste-water analysis, results of the current study depict a higher consumption of most inquired drugs in Berlin than all other existent studies from Germany and other countries. In an international study of comparisons between nightlife scenes in Europe, Berlin, compared to other European central cities and capitals, showed significantly higher consumption of amphetamine, but less cocaine [3]. Compared to a study investigating French-speaking Switzerland, Berlin showed higher consumption rates according to our study (30-days prevalence: Cannabis: 62 vs. $54 \%$, MDMA 49 vs. $23 \%$, and cocaine 36 vs. $21 \%$, all respectively; [1]). This higher prevalence of drug consumption in Berlin was not only prevalent in international comparisons, but also in nation-wide comparisons. In a comparison of our results to the study 


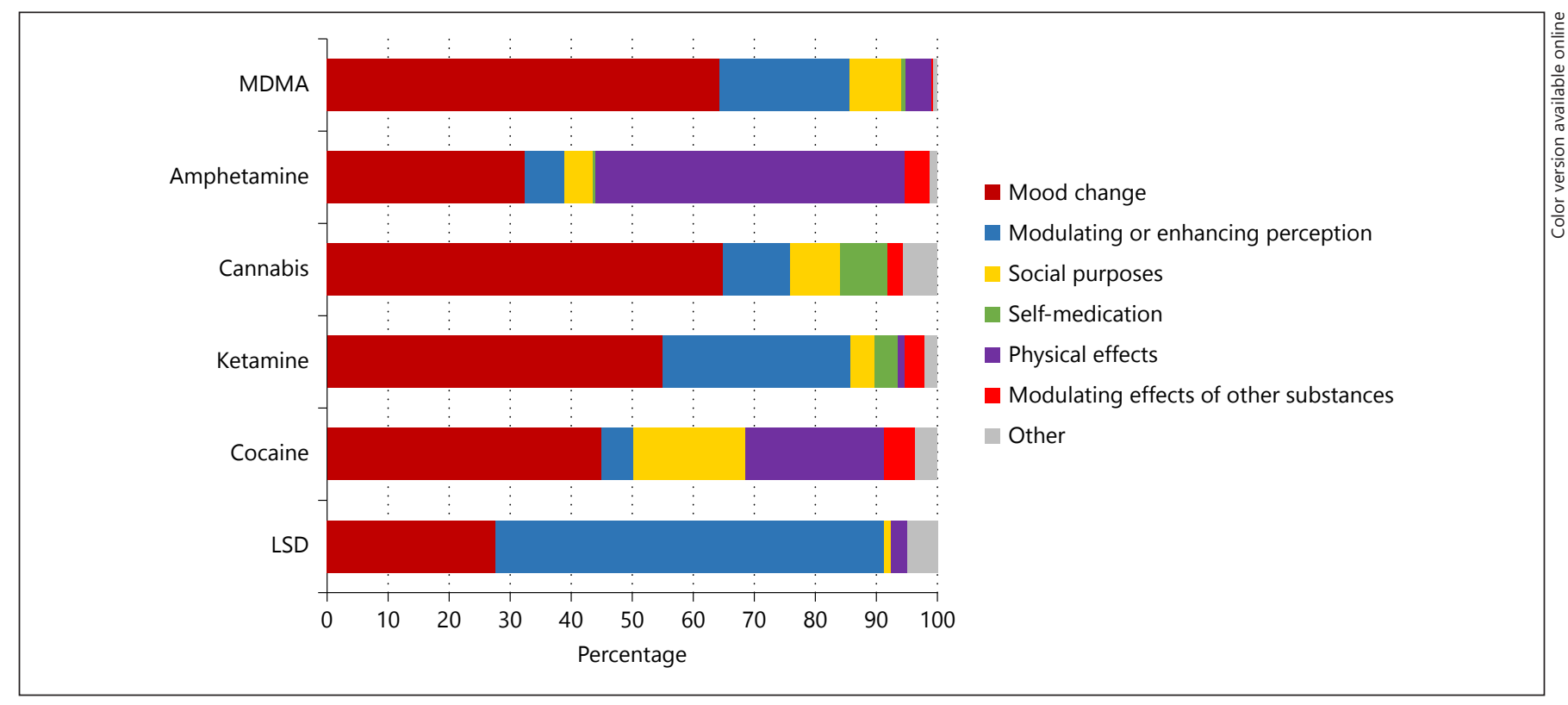

Fig. 4. Distribution of the stated motivations for the use of the 6 most commonly used substances in the party scene. MDMA, 3,4-methylendioxy-N-methylamphetamin.

concerning the Munich party-scene by Hannemann et al. [2], Berlin party-goers exhibited equal (cannabis) or higher (all other) drug use (12-month prevalence was reported here; cannabis: 80 vs. $81 \%$, MDMA: 74 vs. $64 \%$, amphetamine: 70 vs. $60 \%$ and cocaine: 62 vs. $40 \%$ ).

Additionally, within the city of Berlin, consumption seems to have increased over the last years. A comparison of the results from this study with the results from the study by Tossmann et al. [3] indicates an increase in both lifetime and 30-day prevalence: cannabis: lifetime prevalence: 94 vs. $79 \%$ and 30 -day prevalence: 62 vs. $55 \%$; amphetamine: 79 vs. $46 \%$ and 50 vs. $24 \%$; MDMA: 84 vs. $45 \%$ and 50 vs. $23 \%$, cocaine: 78 vs. $33 \%$ and 36 vs. $10 \%$.

Accordingly, prevention programs are urgently needed: the participants in this study rated drug-checking to be the most desired prevention method. Critics of drugchecking services mention that drug checking services may seduce people to consume drugs who would otherwise stay away from it. Also, there is the concern, that a tested substance may falsely be considered as a save substance, which can be consumed without any concerns. Furthermore it is being argued that the risky part of, for example, an ecstasy pill, is mainly the desired substance itself, in this case MDMA, not the contaminants [19].

On the contrary, proponents of drug-checking services cite studies that addressed these and other issues, showing promising results: Benschop et al. [20] found that the results of the analysis in combination with an informative interview leads users to discard their substances if the testing resulted in a "bad" ( = contaminated) pill and that users would take less if it was a highly concentrated pill. It was not found that a drug-checking service represents an incentive to consume drugs [20]. An investigation by Hungerbuehler et al. [21] showed that high-risk individuals were especially likely to take part in those programs. Therefore, through drug-checking, it is possible to reach the high-risk group, which typically represents the target group. Drug-checking not only helps by ensuring the purity and concentration of the drugs consumed, but as professionals who perform the drug-checking can have direct interactions with these high-risk individuals, they can offer additional prevention services such as referrals to frontline services or transmitting knowledge and information to the partygoing community. Furthermore, the study by Hungerbuehler et al. [21] showed no increase in drug consumption by people who use drug-checking services, neither in terms of frequency nor number of substances. In addition to this, for many users, drug-checking services represent the first prevention programs they get in contact with. It therefore may serve as a low-threshold service, which may redirect users with substance abuse or dependency to services with higher thresholds, which they otherwise would maybe not get in contact with [20]. 
Also, drug-checking as a valuable tool for market monitoring of both substances and the behavior of users has been pointed out $[22,23]$.

The study at hand did not find a correlation between the different motives of substance use and request for counseling. Given the fact that all listed prevention offers were rated as useful (at least 4.0), the findings show that all of the motivations should be taken into account by potential prevention programs.

The current study also showed that $20.4 \%$ of the participants have or have had a psychiatric disorder in the past. While this number seems high, a nation-wide comparison shows that it is below average. Jacobi et al. [24] stated that in Germany, the lifetime prevalence for a psychiatric disorder is at $43 \%$, with the 12 -month prevalence in 2014 at $27.7 \%$. However, the mean age and the lifetime prevalence in the cohort of the study by Jacobi et al. [24] are higher than in this study: for the corresponding age group (1829), the prevalence was at 33.5\% [25]. Addictive disorders were stated less frequently than in a study on substance use and addiction in Germany [26]. Generally speaking, two opposing factors could have led to biased results here: On the one hand, the reported prevalence could be increased by self-diagnoses, even though diagnosed disorders were asked for. On the other hand, however, due to the intimacy of the questions, the respondents might have answered in a socially accepted way, which could have led to decreased prevalence rates. These points have to be considered when interpreting data. The results show that participants with a positive CAGE-AID more often associate with "having a psychiatric disorder" or "have had a psychiatric disorder". Regarding the appearance of a psychiatric disorder, the extent of substance use could play a moderating role. This should be investigated in future studies.

The study showed a trend towards participants who suffer from a psychiatric diagnosis, being more likely to use substances more often as self-medication and less often to change their mood, in terms of, for example, "just having fun", than healthy participants. This may imply that existing and future prevention programs might increase their awareness towards counseling of risks and problems that could arise, when self-medication is done by users without professional support. It may also be translated into a stronger cooperation between prevention/counseling services and (mental) healthcare professionals. This finding, however, did not reach significance, when a conservative Bonferroni correction for multiple testing was performed, so caution is advised, when interpreting these findings.

In this study, $76.3 \%$ of the participants stated to be heterosexual, and $22.6 \%$ stated a different sexual orientation (homosexual, bisexual, and other). According to a study by Dalia Research [27], 7.4\% of the German population stated that they were either homosexual, bisexual or transgender. This difference of over 15\% could be explained by this study taking place in Berlin, a metropolitan city, and in a specific scene in which open sexual concepts are to be expected. Further, our rate of $76.3 \%$ heterosexuals aligns with the Global Drug Survey, which showed that $77 \%$ of those surveyed in Berlin were heterosexuals [9]. Considering the study by Lea et al. [28], which identified nonheterosexuals as a high-risk group for risky substance use in the party scene, the proportion of this particular group in the party scene underlines the importance of development of adequately sensitive programs.

The "Epidemiological Survey of Substance Abuse" showed that amongst the general population of Germany, men use substances more often than women [29]. However, findings of studies focusing on nightlife substance use are inconsistent [30]. Our study did not find a significant difference in substance use (i.e., lifetime substance use or problematic substance use) between genders. Concerning the field of prevention services in Berlin, this may imply that counseling/prevention should focus less on gender per se and rather on other (proven) risk factors like sexual preferences, regardless of gender [30-32].

With a mean of $39 \%$ of college graduates, the educational background of those surveyed in our study was slightly higher than the corresponding age group of the Berlin general population of $24-44$ years old (32\%). Similarly, $74 \%$ of our surveyed cohort were at least highschool graduates (39\% college graduates, 35\% highschool graduates), which exceeds the mean $(60 \%)$ of the corresponding age group of the general population. On the contrary, the $4 \%$ unemployment rate found in this study is below the average of Berlin's unemployment rate of the general population (8\%) [33]. Similar results were found in an investigation in Oslo: $63 \%$ of the respondents were high-school graduates, $29 \%$ university students, and $4 \%$ were unemployed [34]. When interpreting data, a sample bias has to be considered: it has to be considered that self-reflected consumers, with a higher tendency to a high academic level, might be more likely to participate in a study on substance use and prevention offers. With respect to the high proportion of university students in the sample, they can be discussed as a target group for prevention programs in universities [32].

\section{Limitations}

Our study has several limitations: one limitation is the selection of the participating clubs, which could have 
led to distortions in the data. When collecting data in the field, only a limited number of locations were included. This was caused by limited capacity of the research team, and the missing openness of some event managers to participate in this study. This limitation could have led to a bias towards the participation of bigger clubs, where only certain styles of music are represented. To counteract such a bias caused by the club selection, an online questionnaire was used concurrently. The online questionnaire was presented in various online portals and other channels which made it possible to reach all clubs and events which met the inclusion criteria.

The comparison of the 2 sets of data (online and paperpencil) showed a similar distribution of the prevalence, with no difference in the distribution of gender and moderate differences regarding certain sociodemographic data (age and educational background). The difference in age distribution between on site and online reporting could be explained by the fact that the online questionnaires not only reached the active proportion of the party scene, but also individuals who do not attend the party scene anymore, yet are still attached to the associated online platforms, newsletters, and so on, and thus were able to reach our study. The moderate difference in the educational background, which was higher in the online questionnaire can be interpreted accordingly, as our data show a positive correlation between age and the educational background.

The substances included in the questionnaire for assessment of prevalence were selected not comprehensively but by popularity to keep the questionnaire as short and handy as possible. Following this rationale, we included only the 2 most popular NPS (synthetic cathinones, synthetic cannabinoids [11]) and did not list the other NPS or derivatives. Instead, we included the option "other" where participants could state and specify other substances, if applicable. Even though this aspect may play a minor role, given the small prevalence of NPS in this sample, this limitation should be considered when interpreting the data.

The methodology of self-reports is one further limitation. Even through a plausibility filter, it is impossible to adequately prove the veracity of the statements. Additional conditions of the investigation, including possible intoxication of the participants, could have led to distortions of data. Concerning possible intoxication, only time-consuming and expensive methods like drug tests can rule this out. Furthermore, the collected data from the Berlin party scene cannot be generalized to the overall population, and therefore no statements on general representation can be made.

Substance Use and Prevention Programs in Berlin's Party Scene

\section{Conclusions}

This work shows a systematic characterization of the patterns of substance use in the current Berlin party scene. Two thirds of participants show risky consumption behavior that goes along with a wish for reducing substance use and for counseling services. Regarding the prevention offers, the participants had specific wishes and ideas, like drug-checking and the development of informative and non-judgmental dialogs. Prevention in this area has been mandated and requested for by the respective scene. Based on the expressed needs and the evaluations of existing drug-checking services in other countries, it should be considered to add this politically controversial tool in Germany to existing prevention programs and evaluate the outcome.

\section{Acknowledgement}

We thank Mr. Charles Li Hui for proofreading the manuscript.

\section{Statement of Ethics}

This study has been approved by the institutional Ethics Committee, and all participants received information about the study beforehand.

\section{Disclosure Statement}

The authors have no conflicts of interest to declare.

\section{Funding Sources}

This study was funded by Berlin Senate Department of Health.

\section{Author Contributions}

F.B.: project coordinator, study design, manuscript draft. F.E.: data collection, data handling, manuscript draft. J.H.: data collection, data handling. L.V.: data collection, supportive administrative tasks, proofreading. L.R.: data collection, supportive administrative tasks. S.M.: English proofreading of the manuscript. N.R.-S.: supervision of study design, data collection and data handling, proofreading the manuscript. A.H.: supervision of the project, proofreading the manuscript. A.S.: administrative supervision of the project, proofreading the manuscript. S.K.: support and supervision of all parts of the project, manuscript draft. 


\section{References}

1 Chinet L, Stéphan P, Zobel F, Halfon O. Party drug use in techno nights: a field survey among French-speaking Swiss attendees. Pharmacol Biochem Behav. 2007 Feb;86(2): 284-9.

2 Hannemann TV, Kraus L, Piontek D. Consumption Patterns of Nightlife Attendees in Munich: A Latent-Class Analysis. Subst Use Misuse. 2017 Sep;52(11):1511-21.

3 Tossmann P, Boldt S, Tensil MD. The use of drugs within the techno party scene in European metropolitan cities. Eur Addict Res. 2001 Mar;7(1):2-23.

4 Soellner R. Club drug use in Germany. Subst Use Misuse. 2005;40(9-10):1279-93.

5 Kraus L, Pabst A, Gomes de Matos E, Piontek D. 2012 Epidemiological Survey of Substance Abuse in the Adolescent and Adult Population of Berlin. München, IFT Institut für Therapieforschung, 2014.

6 Coldwell W. Nighlife reports: clubbing in Berlin. The Guardian, 2016.

7 Sullivan P. Berlin nightlife. The Telegraph, 2017.

8 Resident Advisor. Guide to Berlin: Resident Advisor, 2017. Available from: https://www. residentadvisor.net/guide/de/berlin.

9 Maier LFJ, Barrat M, Winstock A. Global Drug Survey 2017. Berlin Nights Conference, 2017.

10 Betzler F, Heinz A, Köhler S. [Synthetic Drugs - An Overview of Important and Newly Emerging Substances]. Fortschr Neurol Psychiatr. 2016 Nov; 84(11):690-8.

11 Verbraucherschutz BdJuf. NpSG - Neue-psychoaktive-Stoffe-Gesetz vom 21. November 2016 (BGBl. I S. 2615), das zuletzt durch Artikel 6 Absatz 8 des Gesetzes vom 13. April 2017 (BGBl. I S. 872) geändert worden ist. In: Verbraucherschutz BdJuf.

12 Leitlinien für die Suchtprävention im Land Berlin, 2006.

13 Betzler F, Ernst F, Helbig J, Viohl L, Roediger L. Substanzkonsum und Präventionsangebote Berlin - Eine Untersuchung zur aktuellen Situation bezüglich des Substanzkonsums und den Erwartungen an Präven- tionsangebote in der Berliner Partyszene, 2018.

14 EMCDDA: Perception of Risks Associated with Drug Use. Lisbon, European Monitoring Centre for Drugs and Drug Addiction, 2004.

15 Brown RL, Rounds LA. Conjoint screening questionnaires for alcohol and other drug abuse: criterion validity in a primary care practice. Wis Med J. 1995;94(3):135-40.

16 Hauptstadtportal: Clubguide, 2017. Available from: https://www.berlin.de/clubs-und-party/clubguide/.

17 Boys A, Marsden J, Strang J. Understanding reasons for drug use amongst young people: a functional perspective. Health Educ Res. 2001 Aug;16(4):457-69.

18 EMCDDA. Wastewater analysis and drugs - a European multi-city study. Lisbon: European Monitoring Centre for Drugs and Drug Addiction; 2018.

19 Winstock AR, Wolff K, Ramsey J. Ecstasy pill testing: harm minimization gone too far? Addiction. 2001 Aug;96(8):1139-48.

20 Benschop A, Rabes M, Korf DJ. Pill TestingEcstasy \& Prävention. Eine wissenschaftliche Evaluationsstudie in drei Europäischen Städten. Amsterdam: Rosenberg; 2003.

21 Hungerbuehler I, Buecheli A, Schaub M. Drug Checking: A prevention measure for a heterogeneous group with high consumption frequency and polydrug use - evaluation of zurich's drug checking services. Harm Reduct J. 2011 Jun;8(1):16.

22 Brunt TM, Nagy C, Bücheli A, Martins D, Ugarte $M$, Beduwe $C$, et al. Drug testing in Europe: monitoring results of the Trans European Drug Information (TEDI) project. Drug Test Anal. 2017 Feb;9(2):188-98.

23 Brunt TM, Niesink RJ. The Drug Information and Monitoring System (DIMS) in the Netherlands: implementation, results, and international comparison. Drug Test Anal. 2011 Sep;3(9):621-34.

24 Jacobi F, Wittchen HU, Holting C, Höfler M, Pfister H, Müller N, et al. Prevalence, co-morbidity and correlates of mental disorders in the general population: results from the Ger- man Health Interview and Examination Survey (GHS). Psychol Med. 2004 May;34(4): 597-611.

25 Statista: Bevölkerungsanteil mit psychischen Erkrankungen in Deutschland nach Geschlecht und Altersgruppe im Jahr 2011. Statista - Das Statistikportal, 2011.

26 Pabst A, Kraus L, Gomes de Matos E, Piontek D. Substanzkonsum und substanzbezogene Störungen in Deutschland im Jahr 2012. Sucht. 2013;59(6):321-31.

27 Dalia Research. 6\% of Europeans identify as Lesbian, Gay, Bisexual, or Transgender. LGBT, 2016.

28 Lea T, Reynolds R, de Wit J. Alcohol and club drug use among same-sex attracted young people: associations with frequenting the lesbian and gay scene and other bars and nightclubs. Subst Use Misuse. 2013 Jan;48(1-2):129-36.

29 Gomes de Matos E, Atzendorf J, Kraus L, Piontek D. Substanzkonsum in der Allgemeinbevölkerung in Deutschland. Sucht. 2016;62: 271-81.

30 Kelly BC, Parsons JT, Wells BE. Prevalence and predictors of club drug use among clubgoing young adults in New York city. J Urban Health. 2006 Sep;83(5):884-95.

31 Boyd CJ, McCabe SE, d'Arcy H. Ecstasy use among college undergraduates: gender, race and sexual identity. J Subst Abuse Treat. 2003 Apr;24(3):209-15.

32 Viohl L, Ernst F, Gabrysch J, Petzold MB, Köhler S, Ströhle A, et al. 'Higher education' - substance use among Berlin college students. Eur J Neurosci. 2019, Epub ahead of print.

33 Zensus 2011: Bevölkerungsstand May 9, 2011. Available from: https://www.statistik-berlinbrandenburg.de/basiszeitreihegrafik/baszensus-bevoelkerung.asp?Ptyp=300\&Sageb= $10011 \&$ creg $=$ BBB\&anzwer $=4$.

34 Nordfjærn T, Bretteville-Jensen AL, EdlandGryt M, Gripenberg J. Risky substance use among young adults in the nightlife arena: an underused setting for risk-reducing interventions? Scand J Public Health. 2016 Nov;44(7): $638-45$. 